\title{
The effectiveness of PD-1 inhibitors in non-small cell lung cancer (NSCLC) patients of different ages
}

\author{
Yingcheng $\mathbf{W u}^{1, *}$, Qianqian Ju${ }^{2,4, *}$, Bei Qian ${ }^{1, *}$, Feng Zhang ${ }^{3}$ and Hui Shi ${ }^{4}$ \\ ${ }^{1}$ Medical School of Nantong University, Jiangsu 226001, China \\ ${ }^{2}$ Laboratory Animal Center of Nantong University, Jiangsu 226001, China \\ ${ }^{3}$ School of Nursing, Nantong University, Jiangsu 226001, China \\ ${ }^{4}$ Department of Thoracic Surgery, Affiliated Hospital of Nantong University, Jiangsu 226001, China \\ *These authors contributed equally to this work and shared the co-first authorship \\ Correspondence to: Hui Shi, email: disney1982@163.com
}

Keywords: PD-1 inhibitor; age; meta-analysis; overall survival; progression-free survival

Received: September 19,2017 Accepted: December 04, $2017 \quad$ Published: December 26, 2017

Copyright: Wu et al. This is an open-access article distributed under the terms of the Creative Commons Attribution License 3.0 (CC BY 3.0), which permits unrestricted use, distribution, and reproduction in any medium, provided the original author and source are credited.

\section{ABSTRACT}

Background: Immunosenescence, the age-related decline of immunity, affects the immune responses of non-small cell lung cancer (NSCLC) patients. Through immune responses, programmed death-1 (PD-1) inhibitors exert their antitumor robustness. In different ages of NSCLC patients, especially the older patients, the effectiveness of PD-1 inhibitors remains unclear. It is still controversial whether pembrolizumab or nivolumab should be used in treating NSCLC patients.

Results: 2,192 NSCLC patients from four phase III RCTs were included. PD-1 inhibitors significantly prolonged the OS in both younger group (<65-year-age) (HR: $0.64,95 \%$ CI: $0.54-0.75, P=0.000$ ) and older group ( $\geq 65$-year-age) (HR: 0.68 , 95\% CI: 0.54-0.81, $P=0.001$ ) than chemotherapy. Among patients aged over 75, no significantly longer OS was observed (HR: $1.02,95 \%$ CI: $0.35-1.69, P=0.971$ ) than controls. In the older group ( $\geq 65$-year-age), HR of OS favors nivolumab rather than pembrolizumab.

Conclusions: Among patients aged over 75, no significantly prolonged overall survival was observed compared with chemotherapy. In comparison with pembrolizumab, nivolumab was associated with better OS in older NSCLC patients ( $\geq 65$-year-age), and better PFS in all NSCLC patients. Older patients, especially those aged over 75 , should be paid more attention to in the future clinical trials, guidelines, and clinical practice.

Methods: The authors included clinical trials testing PD-1 inhibitors (nivolumab and pembrolizumab) compared with chemotherapies in older and younger patients. The authors used the hazard ratio (HR) and $95 \%$ confidence interval (CI) of overall survival (OS) and progression-free survival (PFS).

\section{INTRODUCTION}

The progress of immunotherapy, especially the programmed cell death protein-1 (PD-1) inhibitors, has created a major paradigm shift within the therapeutic landscape of several solid tumors [1-3]. The United States Food and Drug Administration's approval of nivolumab and pembrolizumab had brought hope to the patients and the scientific community $[4,5]$.
In the United States, the incidence of lung cancer was higher in older people based on a 2016 report, and mortality correlated with age of patients [6]. In particular, for patients aged $80-84$, the incidence and mortality reached the peak. The median age at diagnosis of lung was about 70 years. Furthermore, in the clinic, the efficacy and toxicity of chemotherapy was associated with age of nonsmall cell lung cancer (NSCLC) patients [7]. In the field of immune checkpoint inhibitors (ICIs), it was observed that 
effectiveness varies between younger and older patients [8]. Similar phenomena were depicted among melanoma patients [9], urothelial carcinoma patients [10], and renalcell carcinoma patients [11]. Notably, previous research manifested that patients aged more than 75 years might not benefit from immune checkpoint inhibitors [8].

Immunosenescence, which refers to the agerelated decline of immunity, affected the survival of NSCLC patients [12]. From a preclinical perspective, functions of antigen-presenting cells (APCs) altered during immunosenescence [13]. Also, senescent T cells were demonstrated to have a reduced ability to eliminate tumor cells [12]. Since PD-1 inhibitors exert their antitumor robustness through $\mathrm{T}$ cells, chances are that immunosenescence can have a negative influence on the effectiveness in aged patients.

According to previous clinical trials, whether the aged NSCLC patients could benefit from PD-1 inhibitors remained controversial. In older people, little is known whether pembrolizumab or nivolumab should be used. A previous study compared the effectiveness of different ICIs in younger and older cancer patients in general, however, the researchers did not give recommendations for NSCLC patients specifically because of the lack of published data [8]. Hence, we conducted this meta-analysis in order to compare the PD-1 inhibitors in younger and older patients, taking into accounts the best choice of PD-1 inhibitor for the aged people.

\section{RESULTS}

\section{Search results and population characteristics}

In all, 2,192 NSCLC patients from four phase III randomized controlled trials (RCTs) were included in the analysis [15-18]. The trial selection process was illustrated in Supplementary Figure 1. All the trials are phase III RCTs. All the studies assessed the efficacy of PD-1 inhibitors $(n=1,271)$ versus chemotherapies $(n=921)$. The main characteristics of all the trials were available in Table 1.

\section{Primary outcome: overall survival}

1,887 patients from three RCTs were included in the OS analysis [16-18]. Two RCTs divided patients into three subgroups by age, including $<65-, \geq 65$ to $<75$, and $\geq 75$-year-old groups [17, 18]. Nevertheless, one RCT reported two subgroups by using 65-year-old as a cutoff age [16]. Hence, we combine the two groups $(\geq 65$ to $<75$-year-old group and $\geq 75$-year-old group) into one group. In addition, we analyze the overall survival in patients older than 75 particularly $(n=72)$. The fixed-effect model was applied because there was a low heterogeneity $\left(I^{2}=0.1 \%\right)$ in the analysis.
PD-1 inhibitors significantly prolonged the OS in both younger group (<65-year-age) (HR: 0.64, 95\% CI: $0.54-0.75, P=0.000, n=1,095)$ and older group ( $\geq 65$-year-age) (HR: 0.68, 95\% CI: 0.54-0.81, $P=0.001$, $n=792$ ) than chemotherapy (Figure 1). The analysis based on three age-subgroups $(<65-, \geq 65$ to $<75$-yearold group, and $\geq 75$-year-old group) manifested that, among patients older than 75 years old, no significantly longer OS was observed (HR: 1.02, 95\% CI: 0.35-1.69, $P=0.971$ ) (Figure 2). Subgroup analysis by the type of PD-1 inhibitors (nivolumab and pembrolizumab) was also conducted (Table 2 ). In the older group ( $\geq 65$-year-age), HR of OS favors nivolumab (Table 2).

\section{Secondary outcome: progression-free survival}

The PFS analysis was based on four trials, which enrolled a total of 1,610 patients $[15,16,18]$. A study reported PFS result separately for the three age subgroups ( $<65$-, $\geq 65$ to $<75$-year-old group, and $\geq 75$-year-old group) [18], and we combined the HR of the two groups ( $\geq 65$ to $<75$-year-old group and $\geq 75$-year-old group) for further analysis. We use random-effect model due to the high heterogeneity $\left(I^{2}=65.6 \%\right)$. According to our analysis, a significantly prolonged PFS was demonstrated in younger (HR: $0.73,95 \% \mathrm{CI}: 0.61-0.85, P=0.000)$ and older people (HR: 0.62, 95\% CI: $0.49-0.76, P=0.000$ ) with a cut-off age of 65 (Figure 3). Subgroup analysis of PFS by the type of PD-1 inhibitors (nivolumab and pembrolizumab) demonstrated that efficacy of nivolumab was better than pembrolizumab in both younger and older groups (Table 2).

\section{DISCUSSION}

\section{Main findings}

To the best of our knowledge, this meta-analysis was the first study exploring the correlation between ages and NSCLC patients' survival in PD-1 inhibitor treatment. Recent clinical trials suggested the possible effect of age on the effectiveness of PD-1 inhibitors. However, no solid conclusions were made, partly due to the lack of statistical power. Hence, the aim of this study was to verify our hypothesis and provide practical suggestions in NSCLC treatments. We found that, with a cut-off age of $65, \mathrm{PD}-1$ inhibitors were associated with significantly longer OS and PFS in younger and older groups versus chemotherapy. Also, among NSCLC patients aged over 75, no prolonged OS was observed compared with controls. In addition, older patients treated with nivolumab have a better survival (OS and PFS) in comparison with pembrolizumab, and, among younger patients in treatment of nivolumab, a longer OS was observed as opposed to pembrolizumab. The 
Table 1: Characteristics of the studies included in the meta-analysis

\begin{tabular}{|c|c|c|c|c|c|}
\hline $\begin{array}{l}\text { First author, } \\
\text { year }\end{array}$ & Phase & $\begin{array}{l}\text { Type of } \\
\text { NSCLC }\end{array}$ & Arm & $\begin{array}{c}\text { No. of patients for } \\
\text { analysis }\end{array}$ & $\begin{array}{c}\text { Age (years) median } \\
\text { (range) }\end{array}$ \\
\hline \multirow[t]{2}{*}{ Reck 2016} & III & $\begin{array}{l}\text { Advanced } \\
\text { NSCLC }\end{array}$ & Pembrolizumab $200 \mathrm{mg}$ & 154 & $64.5(33-90)$ \\
\hline & & & ICC & 151 & $66.0(38-85)$ \\
\hline \multirow[t]{3}{*}{ Herbst 2016} & II/III & $\begin{array}{l}\text { Advanced } \\
\text { NSCLC }\end{array}$ & Pembrolizumab $2 \mathrm{mg} / \mathrm{kg}$ & 344 & $63 \cdot 0(56 \cdot 0-69 \cdot 0)$ \\
\hline & & & $\begin{array}{l}\text { Pembrolizumab } 10 \mathrm{mg} / \\
\mathrm{kg}\end{array}$ & 346 & $63 \cdot 0(56 \cdot 0-69 \cdot 0)$ \\
\hline & & & Docetaxel & 343 & $62 \cdot 0(56 \cdot 0-69 \cdot 0)$ \\
\hline \multirow[t]{2}{*}{$\begin{array}{l}\text { Borghaei } \\
2015\end{array}$} & III & $\begin{array}{c}\text { Advanced } \\
\text { nonsquamous } \\
\text { NSCLC }\end{array}$ & Nivolumab $3 \mathrm{mg} / \mathrm{kg}$ & 292 & $61(37-84)$ \\
\hline & & & Docetaxel & 290 & $64(21-85)$ \\
\hline \multirow[t]{2}{*}{$\begin{array}{l}\text { Brahmer } \\
2015\end{array}$} & III & $\begin{array}{c}\text { Advanced } \\
\text { squamous } \\
\text { NSCLC }\end{array}$ & Nivolumab $3 \mathrm{mg} / \mathrm{kg}$ & 135 & $62(39-85)$ \\
\hline & & & Docetaxel & 137 & $64(42-84)$ \\
\hline
\end{tabular}

ICC, investigator's choice chemotherapy; NSCLC, non-small-cell lung cancer.

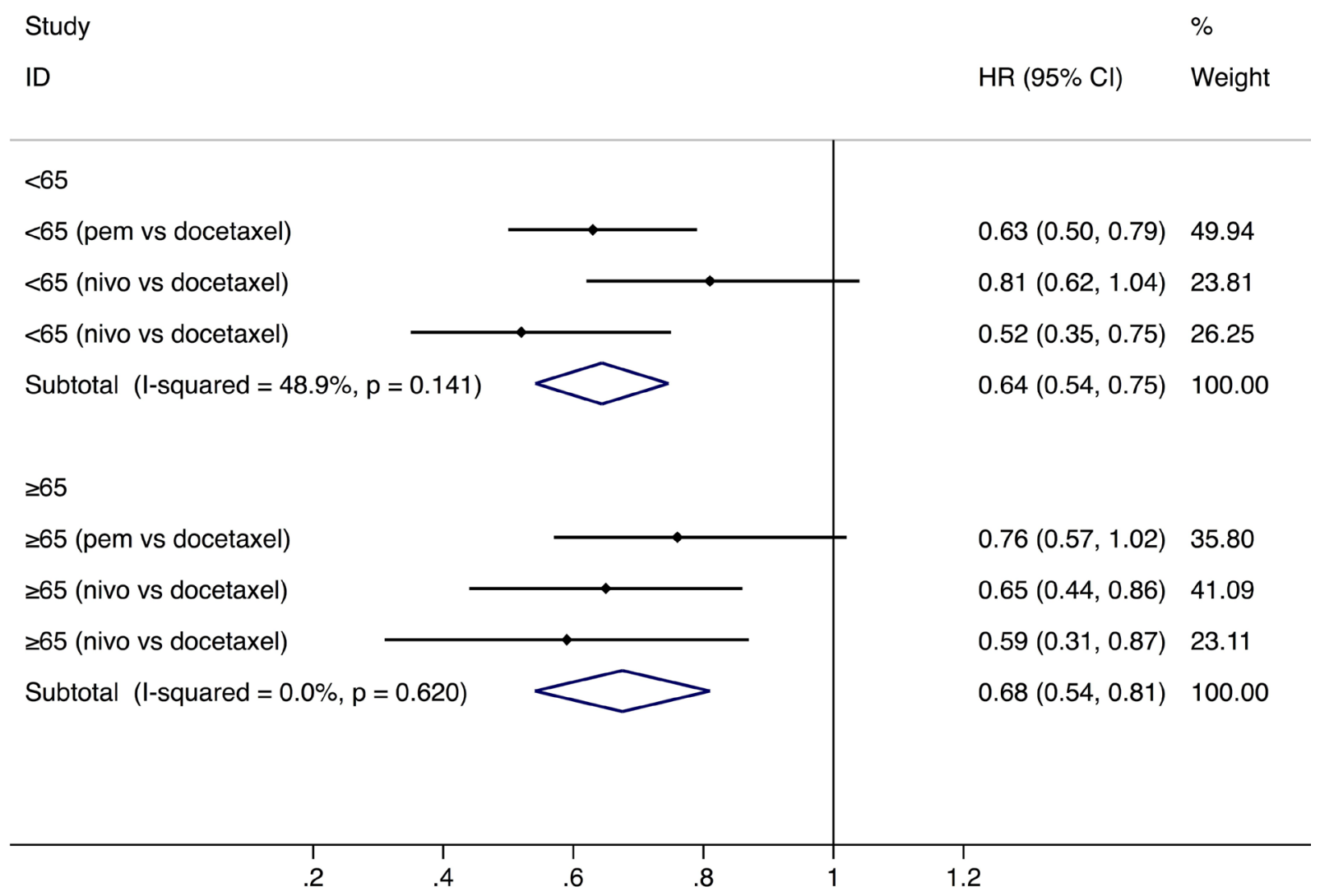

Figure 1: Comparison of overall survival between younger and older groups with a cut-off age of 65. Abbreviations: nivo, nivolumab; pem, pembrolizumab; HR, hazard ratio; CI, confidence interval. 
observed results may not be entirely applicable to all patients treated in the community.

\section{Agreement/disagreement with previous studies and interpretations}

The age-related changes in the innate and adaptive immune system may have varying clinical consequences at different levels, and published reviews have described this phenomenon without a quantifying analysis $[12,19,20]$.

Immunosenescence is a physiological process causing alterations of immune functions resulting from age. Researches on the role of immunosenescence in tumourigenesis provided insights into the possible rationale of age-related reduced efficacy. It was observed that immunosenescence is associated with impaired $\mathrm{T}$ cell activation, reduced tumour antigen release available for processing by antigen presenting cells, and reduced ability of $\mathrm{T}$ cells to eliminate tumor cells [12]. Interestingly, previous study showed that $\mathrm{T}$ cells exhibit senescent changes after 70 years of age [21], which is partly in line with our results. Also, reduced responsiveness of immune cells to cytokines (IL-2 and IL-12) and chemokines, which correlates with reduced trafficking and proliferation, was caused by the increasing age. This may lead to a decrease in the release of neo-antigens, thus impairing the initiation of antitumor immune responses [22]. Notably, CD8+ $\mathrm{T}$ cells were the major mediator influenced by the PD-1 ligand pathway, and aging is associated with a decreased compartment of naïve $\mathrm{CD} 8+\mathrm{T}$ cells [23]. This preclinical finding, in the context of cancer, may partly account for our clinical results. A dialogue between preclinical researchers and clinicians is required for the better understanding and application of PD-1 inhibitors.

Latest clinical studies manifested a possible effectiveness-age correlation in PD-1 inhibitor trials. Scientists in CheckMate 017 trial reported that the HRs of OS did not favored nivolumab in patients aged over 75 years old, which is consistent with our results. Researchers in this trial did not draw a final conclusion, partly attributing it to small sample sizes. Our study, with a extended scope and larger numbers of patients included, reinforced their finding. Another meta-analysis compared the efficacy of different ICIs in varying cancer types in general, however, the absence of specific analysis for NSCLC patients prevented a practical NSCLC guideline for clinicians.

\section{Limitations}

Some limitations of the present meta-analysis should be acknowledged. A major concern was that we include patients with different types of NSCLC with different etiologies and disease courses. We have minimized its influence by using the random-effects model when the heterogeneity was high. Also, subgroup analysis was

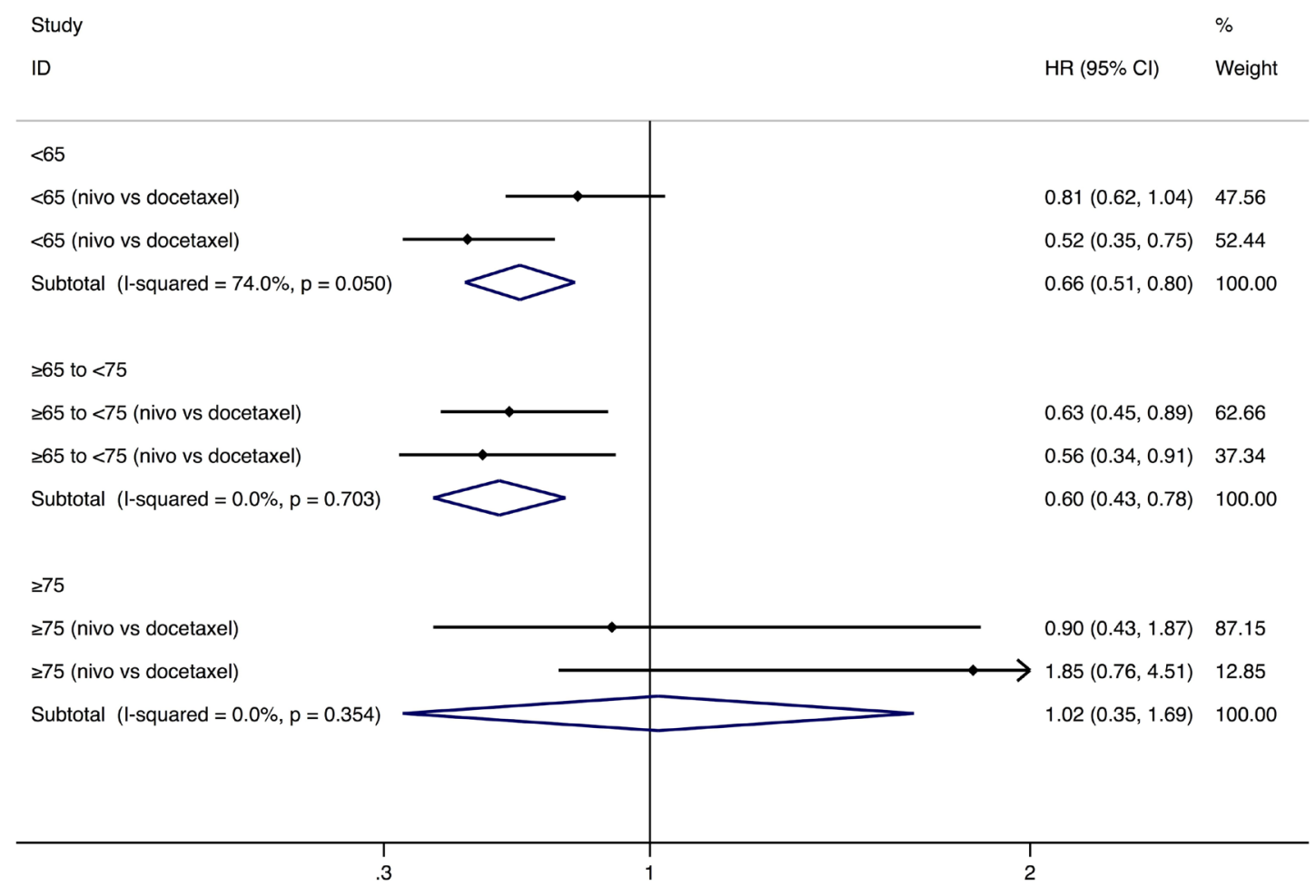

Figure 2: Comparison of overall survival between different ages. Abbreviations: nivo, nivolumab; pem, pembrolizumab; HR, hazard ratio; $\mathrm{CI}$, confidence interval. 
Table 2: Subgroup analysis by the type of PD-1 inhibitors

\begin{tabular}{lcccc}
\hline Age & Type of PD-1 inhibitors & Outcome & HR (95\% CI) & $\boldsymbol{P}$ value \\
\hline$<65$ & Pembrolizumab & OS & $0.63(0.50,0.79)$ & $<0.001$ \\
$<65$ & Nivolumab & OS & $0.66(0.51,0.80)$ & $<0.001$ \\
$\geq 65$ & Pembrolizumab & OS & $0.76(0.53,0.98)$ & $<0.001$ \\
$\geq 65$ & Nivolumab & OS & $0.63(0.46,0.80)$ & $<0.001$ \\
$<65$ & Pembrolizumab & PFS & $0.75(0.53,0.97)$ & $<0.001$ \\
$<65$ & Nivolumab & PFS & $0.62(0.40,0.85)$ & $<0.001$ \\
$\geq 65$ & Pembrolizumab & PFS & $0.69(0.22,1.16)$ & 0.004 \\
$\geq 65$ & Nivolumab & PFS & $0.54(0.29,0.79)$ & $<0.001$ \\
\hline
\end{tabular}

based on relatively small sample sizes, and those data required further evaluation in prospective randomized clinical trials. Especially in the group of patients over 75 years old, the outcome was based on a comparatively small sample size, although the results were in accordance with a former study [8]. Our study only include four RCTs, which may cause the unobserved heterogeneity. This may partly lead to some uncertainties of outcomes. In the future, a potential meta-analysis identified was comparison on toxicity of ICIs between males and females, although valid data are currently absent. The preclinical mechanism is worth further investigations.

\section{CONCLUSIONS}

With a cut-off age of 65 , significantly longer overall survival and progression-free survival were observed in younger and older NSCLC patients treated with PD-1 inhibitors versus chemotherapy. Among patients aged over 75 , no significantly prolonged overall survival was observed compared with chemotherapy. In comparison with pembrolizumab, nivolumab was associated with better overall survival in the older NSCLC patients ( $\geq 65$-year-age), and better progressionfree survival in both younger and older people. Older

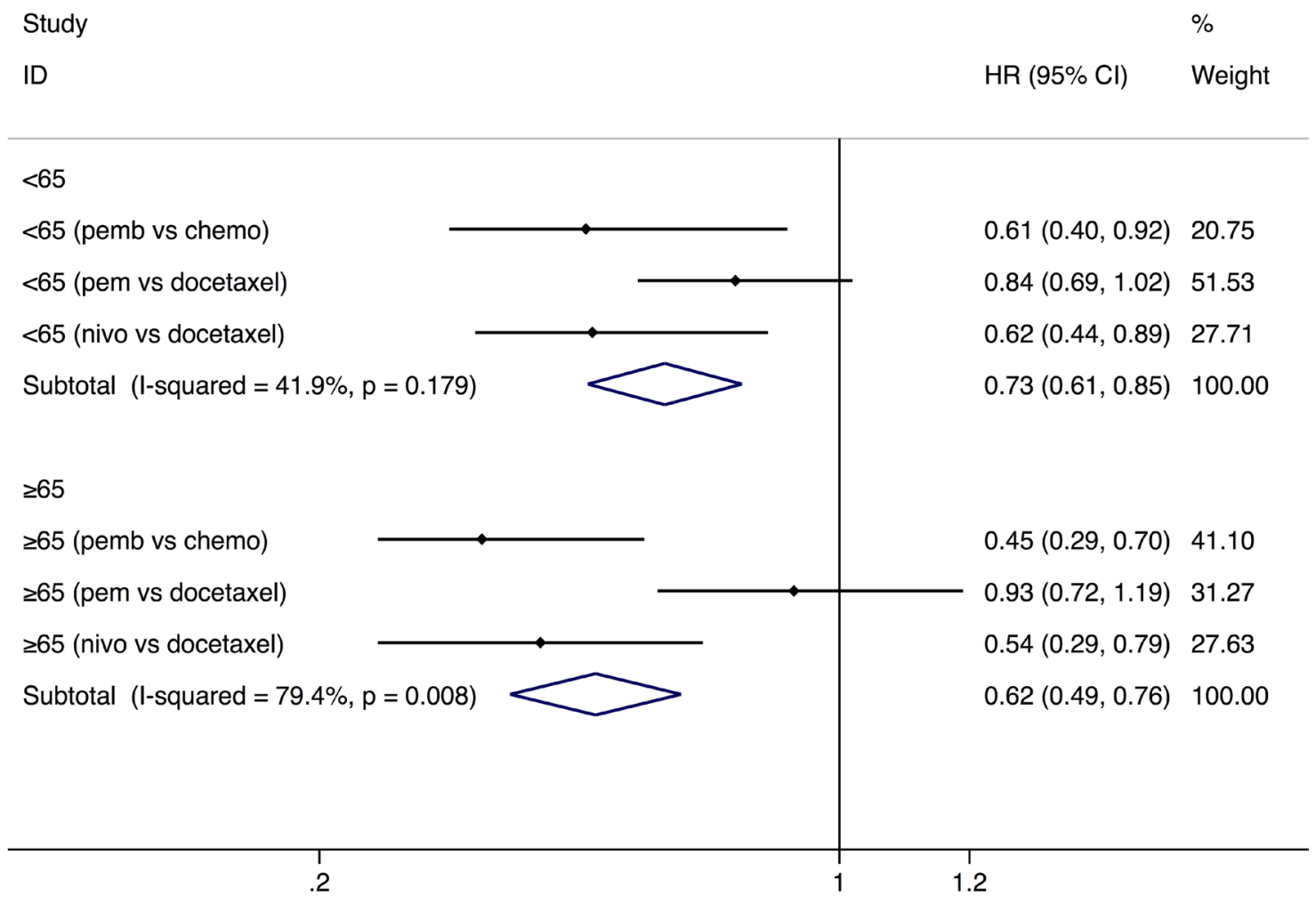

Figure 3: Comparison of progression-free survival between younger and older groups with a cut-off age of 65 . Abbreviations: nivo, nivolumab; pem, pembrolizumab; HR, hazard ratio; CI, confidence interval. 
patients, especially those aged over 75 , should be paid more attention to in the future clinical trials, guidelines, and clinical practice.

\section{METHODS}

\section{Study design and search strategy}

This meta-analysis was based on data from RCTs, which compared PD-1 inhibitors with chemotherapies in younger and older NSCLC patients. We searched for trials on PubMed/Medline, Embase, the Cochrane Central Register of Controlled Trials (CENTRAL), and Google Scholar; September 2017 was the cut-off date. Key words included PD-1 inhibitor, pembrolizumab, nivolumab, age, and clinical trial. All the studies of potential interest were retrieved.

\section{Selection criteria}

Eligible studies should fulfill the following criteria. (1) Trials that included patients with NSCLC. (2) Interventions of PD-1 inhibitors (pembrolizumab and nivolumab). (3) Trials that compared PD-1 inhibitors and chemotherapies. (4) Trials that reported Hazard ratios (HRs) of overall survival (OS) or progression-free survival (PFS) and subgroup analysis by age. (5) Phase III RCTs. Trials would be excluded if the control group is ICI immunotherapy. All the articles that were not published in English were excluded.

\section{Data extraction}

Three reviewers (YW, FZ, HS) independently extracted data with a piloted extraction form, and checked all the data very carefully. We identified all studies by first author and the year of publication, and extracted the following information from the reports: Year of publication, inclusion or exclusion criteria, sample size, drugs and doses in the experimental groups and control groups, HR of PFS or OS in younger and older patients. The primary outcome measured in the meta-analysis was the OS, and secondary outcome was the PFS. All the duplicated studies were excluded.

\section{Risk of bias assessment}

Three reviewers (YW, FZ, HS) independently assessed the risk of bias using the Cochrane Collaboration tool. All disagreements were resolved by the first author (YW). Details on the risk of bias in eight studies are illustrated in Supplementary Figure 2.

\section{Statistical analysis}

Statistical analysis, forest plots, and detection of publication bias were done with Stata SE 14 (StataCorp,
College Station, TX, USA) for macOS Version 10.12.5. Risk of bias was calculated using Review Manager (RevMan5.3; The Nordic Cochrane Centre, The Cochrane Collaboration, Copenhagen, Denmark). HRs were used for evaluation and $95 \%$ confidence intervals (CIs) were calculated for each estimate. $P \leq 0.05$ was considered statistically significant. Heterogeneity was considered low, moderate or high for $I^{2}$ values $<25 \%, 25-50 \%$, and $>50 \%$, respectively [14]. If the $I^{2}$ value was lower than $50 \%$, A fixed model would be used; if the $I^{2}$ value was more than $50 \%$, A random model would be used. Publication bias was assessed by both Begg's test and Egger's test.

\section{Abbreviations}

APC: antigen-presenting cell; ICI: immune checkpoint inhibitor; NSCLC: non-small cell lung cancer; OS: overall survival; RCT: randomized controlled trial; PD-1: programmed death-1; PFS: progression-free survival.

\section{CONFLICTS OF INTEREST}

No potential conflicts of interest were disclosed.

\section{REFERENCES}

1. Hoos A. Development of immuno-oncology drugs from CTLA4 to PD1 to the next generations. Nat Rev Drug Discov. 2016; 15:235-47. https://doi.org/10.1038/ nrd.2015.35.

2. Wu Y, Jiang M. The revolution of lung cancer treatment: from vaccines, to immune checkpoint inhibitors, to chimeric antigen receptor T therapy. Biotarget. 2017; 1:7. https://doi. org/10.21037/biotarget.2017.05.02.

3. Wu Y, Xu R, Jia K, Shi H. The efficacy of chimeric antigen receptor (CAR) immunotherapy in animal models for solid tumors: A systematic review and meta-analysis. PLoS One. 2017; 12:e0187902. https://doi.org/10.1371/journal. pone. 0187902 .

4. Webster RM. The immune checkpoint inhibitors: where are we now? Nat Rev Drug Discov. 2014; 13:883-4. https://doi. org/10.1038/nrd4476.

5. Wu Y, Shi H, Jiang M, Qiu M, Jia K, Cao T, Shang Y, Shi L, Jiang K, Wu H. The clinical value of combination of immune checkpoint inhibitors in cancer patients: A meta-analysis of efficacy and safety. Int J Cancer. 2017; 141:2562-70. https:// doi.org/10.1002/ijc.31012.

6. Torre LA, Siegel RL, Jemal A. Lung Cancer Statistics. Lung Cancer and Personalized Medicine. Advances in Experimental Medicine and Biology. 2016; 893:1-19. https://doi.org/10.1007/978-3-319-24223-1_1.

7. Fruh M, Rolland E, Pignon JP, Seymour L, Ding K, Tribodet H, Winton T, Le Chevalier T, Scagliotti GV, Douillard JY, Spiro S, Shepherd FA. Pooled analysis of the effect of age 
on adjuvant cisplatin-based chemotherapy for completely resected non-small-cell lung cancer. J Clin Oncol. 2008; 26:3573-81. https://doi.org/10.1200/JCO.2008.16.2727.

8. Nishijima TF, Muss HB, Shachar SS, Moschos SJ. Comparison of efficacy of immune checkpoint inhibitors (ICIs) between younger and older patients: A systematic review and meta-analysis. Cancer Treat Rev. 2016; 45:30-7. https://doi.org/10.1016/j.ctrv.2016.02.006.

9. Robert C, Long GV, Brady B, Dutriaux C, Maio M, Mortier L, Hassel JC, Rutkowski P, McNeil C, Kalinka-Warzocha E, Savage KJ, Hernberg MM, Lebbe C, et al. Nivolumab in previously untreated melanoma without BRAF mutation. N Engl J Med. 2015; 372:320-30. https://doi.org/10.1056/ NEJMoa1412082.

10. Bellmunt J, de Wit R, Vaughn DJ, Fradet Y, Lee JL, Fong L, Vogelzang NJ, Climent MA, Petrylak DP, Choueiri TK, Necchi A, Gerritsen W, Gurney H, et al, and KEYNOTE-045 Investigators. Pembrolizumab as SecondLine Therapy for Advanced Urothelial Carcinoma. N Engl J Med. 2017; 376:1015-26. https://doi.org/10.1056/ NEJMoa1613683.

11. Motzer RJ, Escudier B, McDermott DF, George S, Hammers HJ, Srinivas S, Tykodi SS, Sosman JA, Procopio G, Plimack ER, Castellano D, Choueiri TK, Gurney $\mathrm{H}$, et al, and CheckMate 025 Investigators. Nivolumab versus Everolimus in Advanced Renal-Cell Carcinoma. N Engl J Med. 2015; 373:1803-13. https://doi.org/10.1056/ NEJMoa1510665.

12. Daste A, Domblides C, Gross-Goupil M, Chakiba C, Quivy A, Cochin V, de Mones E, Larmonier N, Soubeyran P, Ravaud A. Immune checkpoint inhibitors and elderly people: A review. Eur J Cancer. 2017; 82:155-66. https:// doi.org/10.1016/j.ejca.2017.05.044.

13. Grolleau-Julius A, Harning EK, Abernathy LM, Yung RL. Impaired dendritic cell function in aging leads to defective antitumor immunity. Cancer Res. 2008; 68:6341-9. https:// doi.org/10.1158/0008-5472.CAN-07-5769.

14. DerSimonian R, Laird N. Meta-analysis in clinical trials. Control Clin Trials. 1986; 7:177-88. https://doi. org/10.1016/0197-2456(86)90046-2.

15. Reck M, Rodríguez-Abreu D, Robinson AG, Hui R, Csőszi T, Fülöp A, Gottfried M, Peled N, Tafreshi A, Cuffe S, O'Brien M, Rao S, Hotta K, et al, and KEYNOTE-024 Investigators. Pembrolizumab versus Chemotherapy for PD-L1-Positive Non-Small-Cell Lung Cancer. N Engl
J Med. 2016; 375:1823-33. https://doi.org/10.1056/ NEJMoa1606774.

16. Herbst RS, Baas P, Kim DW, Felip E, Pérez-Gracia JL, Han JY, Molina J, Kim JH, Arvis CD, Ahn MJ, Majem M, Fidler MJ, de Castro G, et al. Pembrolizumab versus docetaxel for previously treated, PD-L1-positive, advanced non-small-cell lung cancer (KEYNOTE-010): a randomised controlled trial. The Lancet. 2016; 387:1540-50. https://doi. org/10.1016/s0140-6736(15)01281-7.

17. Borghaei H, Paz-Ares L, Horn L, Spigel DR, Steins M, Ready NE, Chow LQ, Vokes EE, Felip E, Holgado E, Barlesi F, Kohlhäufl M, Arrieta O, et al. Nivolumab versus Docetaxel in Advanced Nonsquamous Non-Small-Cell Lung Cancer. N Engl J Med. 2015; 373:1627-39. https:// doi.org/10.1056/NEJMoa1507643.

18. Brahmer J, Reckamp KL, Baas P, Crinò L, Eberhardt WE, Poddubskaya E, Antonia S, Pluzanski A, Vokes EE, Holgado E, Waterhouse D, Ready N, Gainor J, et al. Nivolumab versus Docetaxel in Advanced SquamousCell Non-Small-Cell Lung Cancer. N Engl J Med. 2015; 373:123-35. https://doi.org/10.1056/NEJMoa1504627.

19. Grubeck-Loebenstein B, Della Bella S, Iorio AM, Michel JP, Pawelec G, Solana R. Immunosenescence and vaccine failure in the elderly. Aging Clin Exp Res. 2009; 21:201-09. https://doi.org/10.1007/BF03324904.

20. Elias R, Karantanos T, Sira E, Hartshorn KL. Immunotherapy comes of age: Immune aging \& checkpoint inhibitors. J Geriatr Oncol. 2017; 8:229-35. https://doi. org/10.1016/j.jgo.2017.02.001.

21. Farber DL, Yudanin NA, Restifo NP. Human memory T cells: generation, compartmentalization and homeostasis. Nat Rev Immunol. 2014; 14:24-35. https://doi.org/10.1038/ nri3567.

22. Fang M, Roscoe F, Sigal LJ. Age-dependent susceptibility to a viral disease due to decreased natural killer cell numbers and trafficking. J Exp Med. 2010; 207:2369-81. https://doi. org/10.1084/jem.20100282.

23. Shao H, Ou Y, Wang T, Shen H, Wu F, Zhang W, Tao C, Yuan Y, Bo H, Wang H, Huang S. Differences in TCRVbeta repertoire and effector phenotype between tumor infiltrating lymphocytes and peripheral blood lymphocytes increase with age. PLoS One. 2014; 9:e102327. https://doi. org/10.1371/journal.pone.0102327. 